Running head: PROBLEM FINDING, DIVERGENT THINKING AND EVALUATIVE SKILLS

\title{
Problem Finding and Evaluative Thinking among Gifted and Nongifted Students
}

\author{
Abdulla Alabbasi, A. Mํ., Hafsyan, A. ${ }^{2}$, \& Runco, M. A. ${ }^{3}, \&$ AlSaleh, A. ${ }^{1}$ \\ ${ }^{1}$ Arabian Gulf University, Bahrain \\ ${ }^{2}$ The public Authority for Applied Education and Training, Kuwait \\ ${ }^{3}$ Southern Oregon University, United States
}

"Draft version 1.2, 6/3/202. This paper has not been peer reviewed. Please do not copy or cite without author's permission."

10.31124/advance. 12414812 


\begin{abstract}
Many studies have explored the individual differences, including differences in IQ, higher order thinking skills, and divergent thinking (DT), between gifted and nongifted students. However, little is known about individual differences between gifted and nongifted students in terms of problem finding (PF) ability. Moreover, previous works on gifted students have never explored the association between PF and evaluative thinking. This study examined individual differences in the PF abilities of gifted $(N=175)$ and nongifted students $(N=188)$ and tested the relationship between PF and evaluative thinking, which include the individual ability for self-reflection and the ability to evaluate problems. Multivariate analysis of variance (MANOVA) revealed significant differences between gifted and nongifted students' DT, PF, evaluative thinking, and convergent thinking $(C T)$ with a large effect size $(\eta 2=$ 0.359). Other analyses examined (a) gender differences between participants in PF, DT, and evaluative thinking and (b) the interaction between giftedness and gender. Overall, girls scored significantly higher than boys in evaluative thinking in both DT and PF. Multiple regression analyses showed that DT significantly predicted students' performance on evaluative thinking in PF $\left(R^{2}=.40\right)$. Finally, canonical correlation analyses showed a moderate relationship between GPA and CT on one side, and DT, PF, and evaluative thinking on the other side. There was a moderate-to-strong correlation between DT and PF scores and evaluative thinking scores. Limitations and future directions are discussed.
\end{abstract}

Keywords: gifted, nongifted, problem finding, divergent thinking, evaluative thinking 


\section{Problem finding and evaluative thinking among gifted and nongifted students}

Research on gifted students' unique characteristics have suggested that they differ from nongifted students in many ways. Educators, administrators, and, sometimes, even parents should recognize these differences. Davis et al. (2011) proposed a comprehensive list of characteristics that gifted students supposedly possessed. These included risk-taking, curiosity, open-mindedness, intuitive thinking, independence, self-awareness, and, most importantly, originality (Davis et al., 2011). Originality is an extremely important characteristic because it is a prerequisite for creativity (Runco \& Jaeger, 2012). This is not to say that creativity is synonymous with originality; nevertheless, there is no creative product or idea without some sort of originality.

The originality of gifted students should be recognized when designing educational programs. Gifted students should, for example, learn strategies and tactics that target creative thinking skills. This can be accomplished in many ways, some of which involve infusing originality and other creative thinking skills into the curriculum (Beghetto \& Kaufman, 2010) and teaching creative strategies and tactics outside of school curriculums (e.g., Creative Problem Solving [CPS], the Theory of Inventive Problem Solving [TRIZ], Substitute, Combine, Adapt, Modify, Put to another use, Eliminate, and Reverse [SCAMPER], and classic brainstorming sessions (Runco, 2014; Starko, 2018).

Another very important characteristic possessed by gifted students is their metacognitive maturity. This can be operationalized as their ability for self-reflection and their ability to monitor and evaluate problems (Davis et al., 2011; Sternberg, 2005). Highly creative individuals are not only able to produce novel ideas but also able to judge whether they have produced something worthwhile. Thus, other cognitive and metacognitive processes and skills are essential for any creative behavior. These include (but are not limited to) procedural and declarative knowledge, motivation, problem finding, and evaluation 
(Charles \& Runco, 2000; Guilford, 1968; Mumford \& Connelly, 1994; Runco \& Smith, 1992; Runco \& Chand, 1995; see Figure 1).

Figure 1 around here

The latter two processes - that is, problem finding (PF) and evaluation - are the variables of interest in this current study. They represent often-overlooked dimensions of creativity (Runco \& Chand, 1995). Schwanenflugel et al. (1997) compared gifted and nongifted learners with regard to some cognitive and metacognitive abilities and concluded that gifted students possessed higher metacognitive knowledge than nongifted elementary school children. In addition, Davidson and Sternberg (1984) also conducted a study at the elementary school level and concluded that gifted students differed from nongifted students with regard to their utilized processes for (a) selective encoding (i.e., deciding what information in a problem is relevant), (b) selective comparison (i.e., deciding what information stored in long-term memory is relevant for problem solving, and (c) selective combination (i.e., deciding how to combine elements that have been selectively encoded and compared in order to reach a solution; Sternberg, 2018, p. 860). Davidson and Sternberg (1984) found that gifted students scored higher than nongifted students in insight problems across three kinds of insights (i.e., selective encoding, selective comparison, and selective combination), suggesting that gifted learners possessed higher-level skills for (a) deciding what information is relevant or irrelevant to a problem, (b) synthesizing isolated pieces of relevant information, and (c) relating newly acquired information to information acquired in the past.

Other metacognitive skills that have been studied in gifted individuals include planning (Grover, 1987), monitoring (Snyder et al., 2011), metacognitive knowledge (Schraw 
\& Graham, 1997), and self-regulation (Oppong et al., 2019). However, no empirical studies have investigated the relationship between intrapersonal evaluation and PF among gifted learners. This study sought to bridge this research gap. Intrapersonal evaluation is defined as an individual's ability to accurately judge an original idea that he or she has produced. PF refers to the "ability to imagine and look for discrepancies and apparent contradictions, and it entails new hypotheses about old problems/issues or generates entirely novel questions or problems to be solved" (Carson \& Runco, 1999, p. 168).

With a few exceptions (e.g., Hoover \& Feldhusen, 1990; Hoover, 1994; Porath, 1984; Reed, 1992), PF has rarely been studied in gifted education literature, which is surprising given the significance of this psychological process (Einstein \& Infeld, 1938; Mackworth, 1965). Most of these works have employed correlational design, and little is known about possible differences between gifted and nongifted learners in terms of their PF ability.

PF is a necessary skill (or set of skills; Abdulla \& Cramond, 2018; Runco, 1994) for preparing students for the unforeseeable future (Runco, 2016). Real world problems are not always well defined, and they do not always present themselves to the problem solver; rather, they require definition, identification, finding, and discovering problems that do exist or even those that will exist in the future.

The confusion surrounding the Coronavirus Disease 2019 (COVID-19) pandemic presents one example of the lack of PF skills. While there are certain ways to mitigate the pandemic, the exact nature of the pandemic remains unidentified. Is it genetic and an issue of mutation? Or is it a problem involving anti-bodies? Problems must be operationalized before they can be solved efficiently. One might ask where are the gifted and talented students who were enrolled in gifted programs and who were taught many strategies including creative problem solving? One of the answers is that many gifted programs tend to emphasize problem solving but not PF. Indeed, these two skills are different (Mackworth, 1965). This is 
why almost all models for creative processes include PF as a separate step for creative problem solving (e.g., Isaksen et al., 2000; Merrifield et al., 1962; Parnes, 1967; Wallas, 1926). PF's importance in this regard has also been attested by a recent meta-analytic review on the relationship between PF and creativity (Abdulla et al., 2020), where the results showed that PF and creativity were significantly correlated $(r=.22)$. Although this effect size is considered small, it is similar to the effect size reported by Kim (2008) in another metaanalysis on the relationship between creativity and divergent thinking (DT). Thus, educators should assign more weight to PF in gifted programs.

Given these considerations, this current study aimed to (a) examine possible differences between gifted and nongifted students in terms of their PF and evaluative thinking abilities, (b) examine gender differences with regard to PF and evaluative thinking abilities, and (3) investigate relationships among PF, DT, convergent thinking (CT), and evaluative skills while analyzing them to determine whether such relationships differ between gifted and nongifted participants.

\section{Methods}

\section{Participants}

The current study's participants included 359 students from Grades 7 to 9 (171 boys and 188 girls). The sample consisted of both gifted students ( $n=175 ; 82$ boys, 93 girls) and nongifted students ( $n=188 ; 89$ boys, 95 girls). The participants' ages ranged between 11 and 15 years (mean age: 12.4 years) $(S D=1.12)$. Data for the gifted students were collected from Giftedness Academy in the State of Kuwait, and data for nongifted students were randomly collected from two public schools in the State of Kuwait. Gifted students were identified based on Renzulli's three-ring conception of giftedness (Renzulli, 2005): (a) high scores on an IQ test, (b) high scores on a creativity assessment, and (c) task commitment. The mean GPA was $96.93 \%$ for gifted boys and $97.05 \%$ for gifted girls; whereas, the mean GPA was 
$81.54 \%$ for nongifted boys and $88.54 \%$ for nongifted girls. Prior to data collection, each participant was asked to read and sign a consent form prepared by the authors of this study and revised by the aforementioned center (where the data were sourced) as well as the Department of Education.

\section{Instruments}

\section{Uses Test}

Three tasks from the Uses test, which were devised by Wallach and Kogan (1965), were administered: (a) uses for a spoon, (b) uses for a wheel, and (c) uses for a toothbrush. The verbatim directions for the task were as follows:

People typically use everyday items for specific purposes. Often there are alternative uses for the same objects. For example, a newspaper could be used as a hat or a blanket and many other things. For the following item, list as many alternative uses as you can. The more uses you can think of, the better. Do not worry about spelling.

Responses to the Uses test were scored for fluency, originality, and evaluative thinking. Three hundred and eighty-one different ideas were generated for the spoon task, 261 different ideas for the wheel task, and 312 different ideas for the toothbrush task. Fluency was defined as the number of different ideas related to the given stimuli. Originality was scored based on a 3\% cutoff. Finally, evaluative thinking was scored based on students' intrapersonal judgment of the creativeness of their ideas. After completing each task, participants were asked to circle what they believed to be the most original idea among all the given responses. If the selected idea turned out to be the most original one based on the $3 \%$ cutoff, a student received 1 point in the evaluation score. 


\section{Problem Generation Test}

The second study instrument was the Problem Generation (PG) test (Okuda et al., 1991; www.creativitytestingservices.com), which was used to assess participants' PF ability. The PG test consists of three open-ended tasks that require participants to list as many problems as they can. These problems are related to the following subject areas: (a) home and school, (b) life situations, and (c) health and well-being. Example of a PG task is:

List problems along with your friends, peers, schoolmates (any individual who is approximately the same age as yourself). These problems can be real, or they can also be hypothetical and imaginary. Do not limit yourself; the more problems you can list, the better. Do not worry about spelling and take your time.

The PG test was scored for fluency, originality, and evaluative thinking. Four hundred and twenty-three different ideas were generated for the first task, which involved home and school problems, 503 different ideas were generated for the task involving life situations, and 550 different ideas were generated for the task involving health and well-being. The same method was utilized for scoring fluency, originality, and evaluative thinking in the PG test.

\section{The Quick Estimate of Convergent Thinking Test (QECT)}

The third study instrument was QECT (Turkman \& Runco, 2013; www.creativitytestingservices.com), which consists of 18-items that require participants to identify a missing part of a given image. The directions for QECT were as follows: "Look at the pictures below. Try to find the missing part in each of them, and note down what you think is missing in the space below each picture."

Finally, the students were asked to fill out a demographic questionnaire with items about their age and gender. Information about participants' GPA was obtained from the 
previously mentioned giftedness center, where the main study data were sourced, and the two public schools.

Table 1 around here

\section{Results}

\section{Reliability}

The reliability coefficients for fluency, originality, and evaluative thinking in the DT and PG tests were estimated using Cronbach's Alpha. The results showed that the reliability coefficients for fluency, originality, and evaluative thinking with the Uses test were $.76, .73$, and .63 , respectively. The reliability coefficients for fluency, originality, and evaluative thinking with the PG test were $.83, .70$, and, .74 , respectively.

\subsection{Multivariate Analysis of Variance}

\section{Multivariate Analysis of Variance}

Several MANOVAs were run to examine whether gifted and nongifted students' scores differed in terms of fluency, originality, and evaluative thinking in both PG and Uses tests, QECT, and GPA. The results showed a significant difference between gifted and nongifted students: Wilks' Lambda $F(7,349)=74.88, p<.001$, partial $\eta 2=0.633$. ANOVAs pinpointed significant differences between gifted and nongifted students in terms of fluency and originality in both Uses test and PG tests. More specifically, gifted students overperformed compared to nongifted students in terms of fluency in the PG test: $F(1,358)=$ $77.15, p<.001$, partial $\eta 2=0.179$; this was also the case with originality scores on the PG test: $F(1,358)=84.10, p<.001$, partial $\eta 2=0.192$. In addition, the results showed a significant difference between gifted and nongifted students with regard to their evaluative thinking in the PG test $[F(1,358)=41.10, p<.001$, partial $\eta 2=0.104]$ and their evaluative 
thinking in the Uses test $[F(1,358)=17.90, p<.001$, partial $\eta 2=0.048]$ (see Table 1 for means and SD).

Another MANOVA examined whether boys and girls (both gifted and nongifted) differed with regard to their DT, PF, and evaluative thinking skills. The results attested significant differences between male and female students with regard to all the dependent variables (see Table 2): Wilks' Lambda $F(7,349)=18.11, p<.001$, partial $\eta 2=0.294$. Next, several ANOVAs pinpointed a significant gender difference in each of the dependent variables. Female students scored higher than male students in fluency in the PG test $[F$ $(1,358)=30.62, p<.001$, partial $\eta 2=0.079]$ and in originality in the PG test $[F(1,358)=$ 24.16, $p<.001$, partial $\eta 2=0.064]$. Girls also scored significantly higher in evaluative thinking in both the PG tests $[F(1,358)=11.76, p=.001$, partial $\eta 2=0.032]$ and the Uses tests $[F(1,358)=5.14, p=.02$, partial $\eta 2=0.014]$.

The third MANOVA was conducted to examine the interaction between giftedness and gender. A significant interaction was observed between giftedness and gender [Wilks' Lambda $=F(7,349)=29.74, p<.001$, partial $\eta 2=0.406]$. ANOVA tests indicated that gifted female participants scored higher than gifted male participants in fluency in the PG test $[F(1,358)=14.48, p<.001$, partial $\eta 2=0.039]$, while there was no significant difference between gifted males and females in originality in the PG test $[F(1,358)=.45, p=.505$, partial $\eta 2=0.001]$. Finally, the results showed that there were no significant gender-based differences between the gifted and the nongifted students in terms of their evaluative skills in the Uses test $[F(1,358)=.025, p=.875$, partial $\eta 2=0.00]$, while there was one significant difference between male and female participants with regard to their evaluative skills in the PG test $[F(1,358)=79.92, p<.001$, partial $\eta 2=0.184]$. 
Table 2 around here

\section{Correlations and Multiple Regression}

Tables 3, 4, and 5 show correlations between study variables for gifted, nongifted, and the total sample. The relationship between PF and evaluative thinking in the total sample ranged between .35 and $.37(p<.001)$. The results also showed that the relationship between PF and evaluative thinking differed between the gifted and nongifted samples.

Tables 3, 4, and 5 around here

Multiple regression analyses were conducted to examine the association between independent variables and evaluative thinking, controlling for possible overlap in the predictors. First was an analysis examining the association of DT with evaluative thinking in the PG test. The results showed that the model was significant $\left[R=.63, R^{2}=.40, F(4,354)=\right.$ $59.21, p<.001]$. The same result was obtained when evaluative thinking was entered as a dependent variable in the Uses test $\left[R=.70, R^{2}=.48, F(4,354)=83.37, p<.001\right]$. The third regression analysis examined the effect of QECT and GPA on evaluative thinking from the PG test. The result showed that the model was significant and that these two predictors accounted for $16.3 \%$ of the overall variance within the dependent variable $\left[R=.40, R^{2}=.16\right.$, $F(2,356)=34.54, p<.001]$, while they only accounted for $6.2 \%$ of the overall variance in evaluative thinking in the Uses test $\left[R=.25, R^{2}=.06, F(2,356)=11.74, p<.001\right]$. Together, age and gender accounted for less than $5 \%$ of the overall variance in evaluative thinking with regard to DT and PF. 


\section{Canonical Correlation Analysis (CCA)}

Three CCAs were computed for the gifted sample, three for the nongifted sample, and three for the total sample (see Table 6). In the first CCA, set 1 included GPA and QECT, and set 2 included fluency, originality, and evaluative thinking in PG and Uses tests. The analyses showed that the canonical correlation was significant for the gifted sample [Wilks' Lambda $F$ $(12,334)=3.03, R c=.40 p<.001]$ and the nongifted sample $[F(12,352)=4.88, R c=.45, p$ $<.001]$, thus indicating a moderately significant relationship between the two sets.

The second CCA analyzed fluency and originality in set 1 and evaluative thinking in both the Uses and the PG tests in set 2. A moderate-to-strong relationship was observed in the gifted sample $[F(8,338)=25.14, R c=.65, p<.001]$ and the nongifted sample $[F(8,356)=$ 79.16, $R c=.86, p<.001]$.

Finally, the third CCA examined evaluative thinking in both the Uses and the PG tests in set 1 and the QECT and the GPA in set 2. The Wilks' Lambda was also significant in the gifted sample $[F(4,342)=2.88, R c=.25, \mathrm{p}=.02]$ and the nongifted sample $[F(4,360)=$ 9.71, $R c=.39, p<.001]$.

\section{Discussion}

These empirical results indicate significant differences between the DT, PF, and evaluative thinking skills of gifted and nongifted learners. MANOVAs showed that gifted students scored higher on evaluative thinking, PF, DT, and CT compared to nongifted students, and there was a large effect size $(\eta 2=0.359)$. Furthermore, when gifted and nongifted students were compared in terms of evaluative thinking PF skills, the results showed a significant difference between the two groups with a medium effect size $(\eta 2=$ 0.104). These findings demonstrate that gifted students were more capable of originating novel ideas compared to nongifted learners (Davis, 2003); furthermore, they also had a higher capability to evaluate the creativeness of their ideas. Thus, this current study recommends 
that gifted programs should provide more space for gifted learners to work with ill-defined problems in order to encourage them to find and discover novel problems; as Torrance (1966) put it, to be sensitive to problems and gaps in knowledge.

Unlike previous findings regarding gender differences in PF, (i.e., Hoover, 1994; Hoover \& Feldhusen, 1990), the ANOVA results showed that gifted females scored significantly higher than gifted males with regard to PF. This may have been the case because, in this study, PF was assessed differently compared to the Formulation Hypotheses Test utilized by Hoover (1994) and Hoover and Feldhusen (1990).

Multiple regression analysis indicated that DT significantly predicted students' performance in evaluative thinking. Moreover, CCA results suggested that DT was moderately-to-highly associated with evaluative thinking. This relationship finding nearly agrees with that of previous research on DT and evaluative thinking (Runco, 1992; Runco \& Basadur, 1993). This may be the case because both are ideational processes, and moreover, producing ideas (i.e., DT) probably helps a student practice evaluating ideas.

\section{Conclusion}

Our study's major educational implications were as follows: It is important to (a) teach PF skills to gifted students along with other skills such as DT, creative problem solving, and critical thinking skills, (b) encourage educators to provide gifted students with more opportunities to work with ill-defined problems, and (c) spread awareness among educators that gifted students are capable of producing original ideas for ill-defined problems and of evaluating their ideas' appropriateness.

Finally, this study had two limitations, which are worth mentioning here. First, our sample consisted of academically gifted students. Future researchers could look at the relationship between PF and evaluative thinking across different types of giftedness including mathematical, artistic, and scientific giftedness in students. Finally, future research could also 
examine the role of flexibility on evaluative thinking skills in addition to fluency and originality. 


\section{References}

Abdulla, A. M., \& Cramond, B. (2018). The creative problem finding hierarchy: A suggested model for understanding problem finding. Creativity. Theories-ResearchApplications, 5(2) 197-229. https://doi.org/10.1515/ctra-2018-0019

Abdulla, A. M., Paek, S., Cramond, B., \& Runco, M. A. (2020). Problem finding and creativity: A meta-analytic review. Psychology of Aesthetics, Creativity, and the Arts, 14(1), 3-14. https://doi.org/10.1037/aca0000194

Beghetto, R. A., \& Kaufman, J. C. (Eds.). (2010). Nurturing creativity in the classroom. Cambridge University Press. https://doi.org/10.1017/9781316212899

Carson, D. K., \& Runco, M. A. (1999). Creative problem solving and problem finding in young adults: Interconnections with stress, hassles, and coping abilities. The Journal of Creative Behavior, 33(3), 167-190. https://doi.org/10.1002/j.21626057.1999.tb01195.x

Charles, R., \& Runco, M. A. (2001). Developmental trends in the evaluative and divergent thinking of children. Creativity Research Journal, 13, 415-435. https://doi.org/10.1207/S15326934CRJ1334_19

Davidson, J. E., \& Sternberg, R. J. (1984). The role of insight in intellectual giftedness. Gifted Child Quarterly, 28(2), 5864. https://doi.org/10.1177/001698628402800203

Davis, G. A. (2003). Identifying creative students, teaching for creative growth. In N. Colangelo \& G. A. Davis (Eds.), Handbook of gifted education ( $3^{\text {rd }}$ edition, pp. 311 324). Boston, MA: Pearson Education.

Davis, G. A., Rimm, S. B., \& Siegle, D. (2011). Education of the gifted and talented (6th ed.). Boston, MA: Pearson. 
Einstein, A., \& Infeld, L. (1938). The evolution of physics. New York: Simon \& Schuster.

Grover, S. C. (1987). Level of planning skill as a predictor of variations in computer competency among intellectually gifted and non-gifted children. Journal of Educational Research, 80(3), 173. https://doi.org/10.1080/00220671.1987.10885746

Guilford, J. P. (1968). Intelligence, creativity, and their educational implications. San Diego, CA: EDITS.

Hoover, S. M. (1994). Scientific problem finding in gifted fifth-grade students. Roeper Review, 16(3), 156-159. https://doi.org/10.1080/02783199409553563

Hoover, S. M., \& Feldhusen, J. F. (1990). The scientific hypothesis formulation ability of gifted ninth-grade students. Journal of Educational Psychology, 82(4), 838848. https://doi.org/10.1037/0022-0663.82.4.838

Isaksen, S.G., Dorval, K. B., \& Treffinger, D. J. (2000). Creative approaches to problem solving: A framework for change. Dubuque, Iowa: Kendall/Hunt.

Kim, K. H. (2008). Meta-analyses of the relationship of creative achievement to both IQ and divergent thinking test scores. Journal of Creative Behavior, 42, 106-130. https://doi.org/10.1002/j.2162-6057.2008.tb01290.x

Mackworth, N. H. (1965). Originality. American Psychologist, 20(1), 51-66.

Merrifield, P. R, Guilford, J. P., Christensen, P. R., \& Frick, J. W. (1962). The role of intellectual factors in problem solving. Psychological Monographs: General and Applied, 76(10), 1-21. https://doi.org/10.1037/h0093850

Mumford, M. D., \& Connelly, M. S. (1994). Creativity and problem solving: Cognition, adaptability, and wisdom. Roeper Review, 16(4), 241-246. https://doi.org/10.1080/02783199409553589

Okuda, S. M., Runco, M. A., \& Berger, D. E. (1991). Creativity and the finding and solving 
of real-world problems. Journal of Psychoeducational Assessment, 9(1), 45-53. https://doi.org/10.1177\%2F073428299100900104

Oppong, E., Shore, B. M., \& Muis, K. R. (2019). Clarifying the connections among giftedness, metacognition, self-regulation, and self-regulated learning: Implications for theory and practice. Gifted Child Quarterly, 63(2), 102-119. https://doi.org/10.1177\%2F0016986218814008

Parnes, S. J. (1967). Creative behavior guidebook. New York: Scribners.

Porath, M. (1984). IQ, cognitive level, and related information processing variables as predictors of problem finding ability in intellectually gifted children (unpublished master's thesis), The University of British Columbia.

Reed, C. W. (1992, October). Problem finding: An empirical investigation of problem finding and personality characteristics of academically talented and intellectually gifted secondary students. Dissertation Abstracts International, 53, 1103.

Renzulli, J. S. (2005). The Three-Ring conception of giftedness: A developmental model for promoting creative productivity. In R. J. Sternberg \& J. E. Davidson (Eds.), Conceptions of giftedness (p. 246-279). Cambridge University Press. https://doi.org/10.1017/CBO9780511610455.015

Runco Creativity Assessment Battery (2020, April). Creativity Testing Services. Retrieved from https://www.creativitytestingservices.com/products

Runco, M. A. (1992). Interpersonal and intrapersonal evaluations of creative ideas. Personality and Individual Differences, 13(3), 295. https://psycnet.apa.org/doi/10.1016/0191-8869(92)90105-X

Runco, M. A. (1994). Problem finding, problem solving, and creativity. Norwood, N.J: Ablex. 
Runco, M. A. (2014). Creativity: Theories and themes: Research, development, and practice (2nd ed.). Elsevier Academic Press.

Runco, M. A. (2016). We must prepare for the unforeseeable future. In D. Ambrose, \& R. J. Sternberg (Eds.), Creative intelligence in the 21st century. Sense Publishers.

Runco, M. A., \& Basadur, M. (1993). Assessing ideational and evaluative skills and creative styles and attitudes. Creativity \& Innovation Management, 2(3), 166-173. https://doi.org/10.1111/j.1467-8691.1993.tb00088.x

Runco, M. A., \& Chand, I. (1995). Cognition and creativity. Educational Psychology Review, 7, 243-267. https://doi.org/10.1007/BF02213373

Runco, M. A., \& Jaeger, G. J. (2012). The standard definition of creativity. Creativity Research Journal, 24(1), 92-96. https://doi.org/10.1080/10400419.2012.650092

Runco, M. A., \& Smith, W. R. (1992). Interpersonal and intrapersonal evaluations of creative ideas. Personality and Individual Differences, 13, 295-302. https://doi.org/10.1016/0191-8869(92)90105-X

Runco, M. A., Abdulla, A. M., Peak, S., Aljasim, F. A., \& AlSuwaidi, H. N. (2016). Which test of divergent thinking is best? Creativity. Theories-Research-Applications, 3, 4-18. DOI: $10.1515 /$ ctra-2016-0001

Schraw G. \& Graham, T. (1997) Helping gifted students develop metacognitive awareness. Roeper Review, 20(1), 4-8. DOI: 10.1080/02783199709553842

Schwanenflugel, P. J., Stevens, T. P. M., \& Carr, M. (1997). Metacognitive knowledge of gifted children and nonidentified children in early elementary school. Gifted Child Quarterly, 41(2), 25-35. https://doi.org/10.1177/001698629704100204 
Snyder, K. E., Nietfeld, J. L., \& Linnenbrink-Garcia, L. (2011). Giftedness and metacognition: A short-term longitudinal investigation of metacognitive monitoring in the classroom. Gifted Child Quarterly, 55(3), 181-193.

Starko, A. J. (2018). Creativity in the classroom: Schools of curious delight ( $6^{\text {th }}$ Edition). Routledge.

Sternberg, R. J. (2005). Intelligence. In K. J. Holyoak \& R. G. \& R. G. Morrison (Eds.), The Cambridge handbook of thinking and reasoning (pp. 751-773). Cambridge University Press.

Sternberg, R. J. (2018). Context-sensitive cognitive and educational testing. Educational Psychology Review, 30(3), 857-884.

Torrance, E. P. (1966). The Torrance Tests of Creative Thinking-Norms-Technical Manual Research Edition-Verbal Tests, Forms $A$ and B-Figural Tests, Forms $A$ and B. Princeton, NJ: Personnel Press.

Turkman, B., \& Runco, M. A. (2013). Quick Estimate of Convergent Thinking [Measurement instrument]. Retrieved from https://www.creativitytestingservices.com/products

Wallach, M. A., \& Kogan, N. (1965). Modes of thinking in young children: A study of the creativity-intelligence distinction. Holt, Rinehart \& Winston.

Wallas, G. (1926). The art of thought. New York, NY: Harcourt Brace and World. 